\title{
Poder local e condições de sua renovação na Amazônia
}

\section{Local power and the conditions for its reproduction}

Pierre Guilhem Marie-Joseph Teisserenc - Doutor em Sociologia pela Université ParisDescartes, Sorbonne e École des Hautes Études en Sciences Sociales (1973). Professor Emérito da Universidade Paris 13. Fundador do Centre d'Études et des Recherches sur l'Action Locale/CERAL. E-mail: pierre-teisserenc@wanadoo.fr.

\section{Resumo}

Neste artigo são abordadas, sob a perspectiva de uma sociologia empírica do poder, as condições de renovação da estrutura política local na Amazônia brasileira. A partir das experiências de mobilização antes e depois da criação de Resex e de territórios quilombolas, acompanhadas por pesquisas na Ilha do Marajó e no litoral nordeste do estado do Pará nos últimos cinco anos, foi identificada a pertinência da análise sobre as dinâmicas locais de poder, impactadas pela aplicação de instrumentos de política pública geradores de processos de territorialização norteados pelas ideias de desenvolvimento sustentável e garantia de direitos específicos. No âmbito da problemática das mudanças na conformação de um poder local caracterizado pela existência de redes de interações que são, ao mesmo tempo, redes de influência entre os políticos locais e os cidadãos, o objetivo consiste em fazer um balanço e esboçar uma primeira hipótese sobre as relações e confrontos entre as formas tradicionais de exercício do poder, mobilização e inovações institucionais nas estratégias de participação e tomadas de decisão vinculadas a processos de ação pública territorial na Amazônia, nos quais as Resex e os territórios quilombolas são fundamentais.

\section{Palavras-chave}

Poder local. Resex. Território quilombola. Mobilização. Amazônia brasileira.

\begin{abstract}
In this article we address, under a perspective of empirical sociology of power, the conditions of local political structure renovation in the Brazilian Amazon. Based on experiences of mobilization before and after the creation ofResex and Quilombola territory, monitored by research during the last five years, in the Archipelago of Marajó and the Northeast coast of the State of Pará, was identified the pertinence of the analysis on local dynamics of power affected by the use of public political instruments that create processes of territorialisation informed on ideas of sustainable development and guarantee of specific rights. Within the problematic of changes in the conformation of a local political power characterized by the existence of interaction networks that are, simultaneously, influence networks between local politicians and citizens, the objective is to make an assessment and formulate a hypothesis on the relations and confrontation between traditional characteristics of the exercise of power, mobilization and institutional innovation as participation and decision making linked to processes of territorial public action in the Amazon, where Resex and Quilombola territory are fundamental.
\end{abstract}

\section{Keywords}

Local political power. Resex. Quilombola territory. Mobilization. Brazilian Amazon. 


\section{INTRODUÇÃO}

Com base nas pesquisas desenvolvidas na região, temos observado as transformações econômicas, sociais e políticas ocasionadas pela criação e implementação das Reservas Extrativistas (Resex), assim como, mais recentemente, temos acompanhado a mobilização política das comunidades quilombolas localizadas em Salvaterra, um dos municípios da Ilha de Marajó ${ }^{1}$. Desse modo, busca-se apreender a realidade do poder local em contextos da Amazônia brasileira e considerar as mudanças que vêm sendo empreendidas ocorrendo neste território, sob o efeito dessas transformações. Essas pesquisas têm possibilitado, ao mesmo tempo, constatar a ausência de análises sobre o poder local, na perspectiva da sociologia política. Esta abordagem torna-se ainda mais relevante quando se propõe a explicar as mudanças ocorridas no sistema de poder local, particularmente nos processos de criação de Resex, objeto deste artigo, em razão do impacto desse instrumento de política pública em seus respectivos territórios.

Este artigo não pretende descrever de modo exaustivo o modo de funcionamento do poder local na Amazônia brasileira, uma vez que até o presente não foi possível desenvolver um programa de pesquisa que tenha esta questão como objeto central. Assim, trata-se de um primeiro movimento para compreender o poder local a partir do que foi suscitado pelas pesquisas sobre os efeitos territoriais da criação de três Resex, bem como a mobilização política e social das comunidades quilombolas. Essas pesquisas, portanto, não tomaram o poder local como questão norteadora. Dessa forma, o objetivo deste artigo é fazer um balanço do poder local e esboçar uma primeira hipótese, que em breve deve ser colocada à prova por nós mesmos ou por colegas interessados, sempre que houver novas possibilidades de estudos sobre territórios de ação pública na Amazônia.

A abordagem aqui escolhida é a de uma sociologia empírica do poder, inspirada pela sociologia das organizações de Michel Crozier (1964), que considera as redes de interações como base deste poder, importando, por isso mesmo, identificá-las e defini-las. Conta-se, também, como referência importante, os trabalhos de longa data sobre o sistema político-administrativo, realizados na França por Pierre Grémion (GREMION, 1976), retomados por Albert Mabileau (1995) e Alain Faure (2002), em uma análise que demonstrou o seguinte.

\footnotetext{
Estudo realizado pelo autor no período de 2012 a 2014, no âmbito do projeto de pesquisa "Desafios do reconhecimento a comunidades quilombolas: atores, relações e conflitos na Ilha de Marajó (PA)", com financiamento do CNPq. O projeto foi coordenado por Luís Fernando Cardoso e Cardoso, antropólogo e professor da UFPA, a quem muito agradecemos pelo aprendizado, pela convivência, além da oportunidade de colaboração acadêmica.
} 
[...] através da densidade das relações sociais desenvolvidas entre as burocracias territoriais e os políticos locais são estabelecidas relações de poder interiorizadas e institucionalizadas que circunscrevem um modo de exercício do poder: o poder notabiliário (GREMION, 1976, p. 248).

Na França dos anos de 1970, esse poder se apresentava como

[...] um poder de bloqueio, de resistência às injunções do centro, de filtragem da ação burocrática [...] condicionando um modo de exercício da democracia local caracterizado por uma fraca renovação das elites nos postos eletivos e uma dupla transferência de responsabilidade e de legitimidade (GREMION, 1976, p. 254-255).

Nesse contexto bem específico, o sistema em questão baseava-se em relações cruzadas entre os representantes do Estado central e os políticos locais, cujo poder emanava de sua capacidade de obter dos representantes do Estado os recursos necessários para a realização de programas de governo com base na troca de favores.

A partir desta referência, o objetivo é retomar a análise iniciada por Pierre Grémion, não para comparar o sistema de poder local francês com o sistema de poder local brasileiro, mas para elaborar uma análise sociológica do poder local brasileiro, marcado pela existência de redes de interações que são, ao mesmo tempo, redes de influência entre os políticos locais e os cidadãos, que se organizam em um sistema de poder que deve ser definido e caracterizado.

$\mathrm{Na}$ medida em que, diferentemente da realidade francesa, o sistema de poder local brasileiro baseia-se na permanência de um sistema de dominação herdado do período colonial e que continua a influenciar as relações entre os políticos e os cidadãos, é necessário demonstrar a importância da permanência desse sistema e identificar algumas condições do seu enfrentamento. Além disso, esta diferença significativa entre o contexto francês e o contexto brasileiro justifica que, ao referir Pierre Grémion, o foco será dirigido para as estratégias dos atores e não para as estruturas sociais (GREMION, 1976, p. 12) que, embora pouco visíveis, devam ser ligadas a estas.

Uma das pesquisas mais significativas que possibilitou apreender o poder local no contexto amazônico brasileiro tomou por objeto a mobilização das 15 comunidades quilombolas de Salvaterra nas últimas três eleições municipais. A questão principal colocada foi a existência de uma assimetria entre a capacidade de mobilização dessas comunidades pela defesa de seus novos direitos reconhecidos no artigo 68 do Ato das Disposições Constitucionais Transitórias (ADCT) da Constituição Federal (CF) de 1988, e no Decreto Presidencial no 4.887, de 2003, que regulamenta os procedimentos para a titulação definitiva das terras 
onde habitam as populações remanescentes de quilombos - e a incapacidade de impacto dessas comunidades na cena política, quando das eleições municipais.

Para esta assimetria, uma primeira explicação pode estar no fato de que a categoria "quilombola", comumente utilizada para idendificar descendentes de antigos escravos fugidos que arriscaram a vida em busca da liberdade, é uma categoria ambígua e não homogênea, conforme demonstrado em um número considerável de trabalhos sobre esta questão ${ }^{2}$, e que a remete para uma realidade identificada a partir de uma concepção em nada sociológica e/ou antropológica, que seria muito mais de ordem administrativa ou jurídica. De fato, mesmo que esta denominação tenha sido objeto de debates contraditórios entre especialistas do direito e das ciências sociais, o foi legitimado pela Constituição de 1988, tornando-se uma categoria operacional para o enfoque do problema identificado e definido por esta categorização.

Esta assimetria também pode ser explicada pela defasagem entre o contexto local, onde ocorre a mobilização dessas comunidades em defesa de seus direitos, e no qual se poderia esperar uma expressão política desta mobilização em decorrência das eleições municipais, e o quadro geral proposto pela Constituição para a aplicação desses direitos, que atribui os serviços essenciais e as competências na matéria à União, especialmente através do Instituto Nacional de Colonização e Reforma Agrária (Incra), enquanto as autoridades públicas locais praticamente não dispõem de nenhuma competência específica para atuar nesse processo, quanto ao atendimento das demandas desta categoria de cidadãos ${ }^{3}$.

Mesmo que esses dois fatores estejam em parte justificados, eles não são suficientes para explicar de modo satisfatório a assimetria constatada entre a mobilização coletiva das comunidades quilombolas, que permanece no âmbito da defesa de seus direitos e da reivindicação do território junto aos atores públicos nacionais, e o engajamento político de membros dessas comunidades no âmbito local. Para explicar tal assimetria, a partir do momento em que não há "interesses diferenciados" bem definidos ou empreendidos coletivamente para defendê-los, distinguindo a situação dos quilombolas das dos demais cidadãos, as relações entre as comunidades e o poder local dependem essencialmente das estratégias de ação desse poder. Como descrito em muitos trabalhos, trata-se de um poder

\footnotetext{
Esta ambiguidade é, sobretudo, discutida no livro Socioambientalismo e novos direitos. Proteção jurídica à diversidade biológica e cultural, de autoria de Juliana Santilli (2005).

3 De fato, em termos de administração e de gestão das comunidades quilombolas, a nível municipal, as comunidades em questão até o presente não podem esperar vantagens diferenciadas. Isso permitiria explicar porque o desafio local de uma mobilização coletiva para pressionar o poder local perde em pertinência uma vez que os interesses específicos defendidos são relativamente limitados e porque prevalece desde então, em tal contexto, engajamentos políticos individuais que correspondem aos dos demais cidadãos.
} 
originário de um sistema de dominação herdado do período colonial, reestruturado no contexto do Ciclo da Borracha sob a forma do sistema aviamento, e que tendeu a se perpetuar até os dias atuais.

Tal sistema de poder local, que começa a se estruturar ainda no periodo colonial, teria se manifestado especialmente por comportamentos individuais de dependência por parte dos cidadãos locais, o que se pode constatar em todos os domínios da sua vida cotidiana e através das estratégias de ação que testemunham uma interiorização desta dominação ${ }^{4}$, e que poderia ser interpretada como babitus, com base na teoria da reprodução de Pierre Bourdieu (1984).

A seguir, será apresentada primeiramente uma descrição desse sistema e suas principais características, a partir da situação das comunidades quilombolas de Salvaterra, destacando-se, em particular, as dificuldades dessas comunidades de encontrar uma saída política para a mobilização, dada a permanência desse sistema de dominação. $\mathrm{Na}$ sessão seguinte, será justificada a importância desta permanência para compreender o comportamento dessas comunidades e de seus membros, com base nas transformações sociais e políticas verificadas em três municípios do estado do Pará, em decorrência da criação de uma Resex em seus respectivos territórios. A experiência recente de criação dessas Reservas mostra, de fato, que o seu sucesso se dá, em parte, por colocar em xeque o sistema de dominação, abrindo o caminho para uma mudança significativa na estrutura de poder local e uma renovação política através da democracia, da ação participativa e de suas práticas locais.

Ao eleger como referência empírica a experiência das Resex, o objetivo é reforçar a hipótese deste estudo, segundo a qual a assimetria entre a mobilização social das comunidades quilombolas e seu engajamento político se explica, em parte, pelo fato de que o quadro jurídico instituído pela Constituição para tratar essa questão desconsidera o poder local, mesmo que este disponha, efetivamente, de meios para viabilizar tal procedimento. Assim, diferente das Resex, cuja criação garante às comunidades tradicionais o direito de denunciar o sistema de dominação e contribuir para transformações no poder local, a forma de reconhecimento das comunidades quilombolas encoraja a mobilização coletiva em prol da defesa de seus novos direitos, contudo, sem interferir no sistema de dominação a que essas comunidades estão submetidas, o que provavelmente explicaria as dificuldades encontradas para mobilizarem-se politicamente.

\footnotetext{
Entre as condições de existência do fascismo, Theodor Adorno et al. (2006 [1950]) consideraram como fundamental ao êxito da dominação a "personalidade autoritária", cuja estrutura de caráter é descrita como uma mistura de medo e frustração, e uma falta de confiança em si mesmo. As pessoas que têm essa personalidade, segundo os autores, demonstram prazer na própria submissão.
} 


\section{AVIAMENTO E PERENIZAÇÃO DO SISTEMA DE COLONIZAÇÃO}

$\mathrm{Na}$ origem do sistema de aviamento, durante a fase de exploração da borracha, que passou por um desenvolvimento fulgurante no fim do século XIX, atraindo uma intensa migração de trabalhadores, principalmente do Nordeste, região mais pobre e populosa do país. Este sistema fundamenta-se na organização e controle da produção de um trabalhador independente, o seringueiro, tendo à sua disposição um território de colheita, em média de 300 hectares, situado no interior da floresta, onde a única ligação com o mundo exterior se dava por intermédio de um patrão, o seringalista - pequeno comerciante, na maior parte das vezes de quem ele dependia não somente para escoar o produto, mas também para obter os meios de trabalho e de subsistência, fornecidos pelo patrão na forma de adiantamentos, porém os produtos sempre eram mais caros que a borracha comprada. A situação de dependência resultante era forte de tal modo que o seringueiro, sob a ameaça até mesmo de morte, não podia deixar a atividade nem vender a produção para outro patrão. Permanentemente endividado, com os pés e mãos atados ao seringalista, o seringueiro ficava submetido a um sistema de poder que, numa escala local, era quase que absolutamente controlado pelo patrão. Como refere Catherine Aubertin (1996, p. 104), o dono do seringal arranjava casamentos, apadrinhava as crianças, fornecia medicamentos. Em larga escala, o seu poder se baseava nem tanto na posse ou propriedade da terra, o aspecto muito mais determinante do poder do seringalista era o domínio estratégico das vias fluviais, por onde os produtos do extrativismo eram escoados e por onde chegavam as mercadorias pelas quais os seringueiros trocavam o produto do seu trabalho. A oferta de produtos do extrativismo era garantida pelo seringalista a uma rede de clientela, por um lado, e, por outro, a chegada aos seringais dos bens de consumo necessários à realização do trabalho extrativista também dependia dele.

Esse sistema de poder foi tão significativo, a tal ponto que, quando a economia da borracha entrou em crise, primeiro nos anos de 1920, e após a retomada da exploração durante a Segunda Guerra, o seringueiro, sempre endividado monetária e moralmente em relação a um patrão, finalmente encontrava-se em uma situação de trabalhador livre, mas continuava sem recursos, porém, quando o contexto favorecia, muitas vezes pôde permanecer na terra, garantindo o seu autossustento através da pesca, caça, extrativismo florestal ou pequena agricultura. No entanto, o sistema de poder imposto culturalmente permaneceu, atualizando-se em relações clientelistas que ultrapassaram o período do ciclo da borracha. 
Esta situação dos seringueiros e o sistema de poder dele resultante levou à formação de uma identidade cultural particularmente significativa, definida por Enrique Leff (2006) nos seguintes termos.

Os seringueiros não são a atualização de uma identidade orginária; foram formados em um processo social a partir das suas lutas sindicais como trabalhadores no negócio de exportação de latex no século XIX até a invenção de suas reservas extrativistas no estado do Acre, no Brasil. São protagonistas de uma luta pela reapropriação de sua natureza, pela afirmaçao de sua cultura e pela criação de um projeto próprio de sustentabilidade. A geografia traçada pelo seringueiro é o resultado de um movimento no pensamento que acompanha uma ação social que reconfigura identidades coletivas, reorganiza um espaço ecológico e constrói novos territórios teóricos, políticos e culturais (LEFF, 2006, p. 501).

Ao longo destemesmo período, na Ilha do Marajó, em função da Proclamação da República, no final do século XIX, comunidades heterogêneas constituídas principalmente de antigos escravos fugidos continuavam a se organizar de modo autônomo, vivendo à margem, em um ambiente marcado pela permanência de um sistema de dominação que os levou a desenvolver estratégias de resistência para assegurar a sua sobrevivência. Flávio Gomes (2005), a propósito, refere-se à permanência e aos efeitos de um sistema paternalista exercido

[...] até hoje pela elite rural tanto no Marajó como em outras regiões da Amazônia, [cujos] efeitos sobre as comunidades são os de quebrar relações de reciprocidade entre as famílias que compõem essas coletividades mantendo-as sob sua dominação (GOMES, 2005, p. 241).

O sistema de dominação descrito por Flávio Gomes possui as mesmas características do aviamento, confirmando assim o parentesco entre esses dois sistemas e o sistema político que se estrutura no Brasil no período colonial. Nucleado no município, para Maria Isaura Pereira de Queiroz (1976), assim se explica a origem desse sistema político, por ela chamado de mandonismo:

Durante a colônia as dificuldades que encontrou Portugal em dominar e povoar um país do tamanho do Brasil, fizeram com que se fomentasse o poder e a independência dos senhores rurais, que dominavam esses pequenos centros [municípios]; o que havia de importante então eram as lutas dos proprietários rurais enre si para terem o poder, ou as lutas dos mesmos proprietários contra as interferências da Metrópole (QUEIROZ, 1976, p. 19).

A ocupação do solo no Brasil foi ocorrendo nos moldes da grande propriedade nas mãos de poucos, em correspondência a um sistema de poder alimentado numa solidariedade de base familiar "com parentes, aderentes 
e agregados, isto é, laços de dependência consanguínea, material e moral" (QUEIROZ, 1976, p. 18). Nesse modelo, grande parcela da população se submetia ao mando em troca de proteção, junto a quem detinha localmente o poder. Para tal, eram estabelecidos laços de compadrio, como uma condição de integração em um sistema de proteção/exploração que garantia o direito à vida. Esse sistema foi herdado pelo período imperial, que, por sua vez, também o transmitiu ao período republicano.

$\mathrm{Na}$ Amazônia brasileira, a perenização do aviamento e o sistema de dominação herdado da colônia, sob diferentes formas e em contextos socioeconômicos diversos, explica porque ainda hoje ocorrem as mesmas situações de dependência, os mesmos tipos de resistência e lutas similares desenvolvidas pelas comunidades tradicionais, dentre estas o segmento social quilombola, pelo direito de continuarem ocupando os territórios onde vivem há gerações. A respeito das comunidades quilombolas, acrescente-se a essas razões de mobilização a defesa dos novos direitos que lhes foram garantidos a partir da Constituição de 1988.

[...] estas lutas e resistência à escravadão feitas de diversas formas continuam ainda hoje quando comunidades localizadas no município de Salvaterra se autodefinem remanescentes quilombolas, são descendentes desses que por gerações lutaram de diversas maneiras para garantir seu direito à terra e à liberdade (GOMES, 2005, p. 241).

Compreende-se, nessas condições, porque as comunidades quilombolas de Salvaterra conseguiram se mobilizar para defender um interesse coletivo próprio (seus direitos a um território e ao reconhecimento de sua identidade), apesar da heterogeneidade de seus membros; uma heterogeneidade que reforça; de certo modo; o princípio da autodefinição ${ }^{5}$ adotado pelo legislador, conforme as exigências dos direitos internacionais relativos às minorias; e porque, ao mesmo tempo, para estas mesmas comunidades é tão difícil encontrar formas de expressão de um engajamento político, na medida em que colide com a permanência de um sistema de dominação que não foi colocado em pauta pelo disposto na Constituição de $1988^{6}$.

5 A Constituição brasileira prevê a autodesignação como remanescente de quilombo e a organização coletiva em associações comunitárias nos processos pelo reconhecimento do direito coletivo à terra e à identidade.

6 Este aspecto será novamente tratado quando ulteriormente for abordada a situação das populações tradicionais e as respostas dadas pela Constituição de 1988 através de Unidades de Conservação como as Resex, na sequência do movimento social do Acre, liderado por Chico Mendes e seus companheiros. 


\subsection{Efeitos da permanência do sistema de aviamento}

O propósito aqui não é discutir as razões da permanência desse sistema de dominação. O que mais importa é analisar a forma como esse sistema tem conseguido se manter, desde o fim do ciclo da borracha, nos anos de 1950, influenciando os comportamentos e as estratégias dos atores locais em diferentes contextos da Amazônia brasileira. É bem o caso no setor de exploração da madeira analizado por Eliane Cantarino O’Dwyer (2002), que demonstra como

[...] a diversidade de agentes econômicos envolvidos, interligados por uma vasta rede de obrigações contratuais - o sistema de aviamento - assegura o monopólio de comercialização da madeira [...] e reconstitui em novas bases os elementos de um sistema repressor da força de trabalho, ao promover no interior dos rios e da floresta amazônica, uma modernização conservadora que mantém intactos mecanismos de força característicos da situação de aviamento dos seringais". (O'DWYER, 2002, p. 81-82). ${ }^{7}$

Existem grandes semelhanças entre a situação dos trabalhadores do setor da madeira descrita por O'Dwyer e a dos membros das comunidades quilombolas da Ilha do Marajó, especialmente as relações mantidas entre esses comunitários com os fazendeiros da região. Particularmente no âmbito das relações assimétricas, marcadas por uma forte dominação dos fazendeiros, os quilombolas não têm outra escolha senão a de desenvolver estratégias individuais na busca de acordos, caso a caso, fundados em lógicas de proximidade, arriscando criar situações ambíguas que explicam por que, dentro de uma mesma comunidade, certos membros obtêm vantagens, em detrimento de outros. Tais acordos concernem à ocupação e ao uso de terras, à exploração dos recursos naturais da floresta ou dos rios, às trocas de serviços, favores, proteção, em relações muito assimétricas entre fazendeiros e quilombolas. De maneira abusiva, os fazendeiros se consideram proprietários dos rios e, por isso, tendem a se apropriar de parte da produção da pesca em troca de autorização para exploração da floresta ou cultivo em terras ocupadas pelos remanescentes de quilombos. Há relatos até mesmo sobre a venda de terras aos fazendeiros, por habitantes de comunidades quilombolas.

Evidentemente, tais acordos têm inevitavelmente deixado traços que contribuem para explicar porque, hoje em dia, os quilombolas não conseguem se organizar em uma frente comum contra o poder exercido pelos fazendeiros e

Em um artigo sobre as práticas participativas no Brasil, apoiadas na experiência da Resex Verde para Sempre, situada no município de Porto de Moz, Céline Broggi e Martine Droulers (2006) constataram que as "relações tradicionais de clientelismo entre os negociantes e seus clientes, baseadas no endividamento permanente (e em parte fictício) dos clientes são sempre mais fortes em Porto de Moz, particularmente no setor da madeira". 
desenvolver estratégias coletivas de luta contra esse poder, apesar da legitimidade a eles conferida pelo reconhecimento constitucional de seus direitos. Assim sendo, para demonstrar a determinação desse poder, convém referir que um número considerável de interlocutores ouvidos durante as visitas às comunidades evocaram a invasão de uma fazenda vizinha como reação à recusa do fazendeiro de negociar qualquer acordo. Mas, nesse caso, tratava-se de um fazendeiro de origem americana, àquela altura um proprietário recente das terras. Enquanto estrangeiro, o fazendeiro provavelmente não estava informado da existência desses acordos caso a caso ou dos jogos de alianças, em um momento em que as comunidades quilombolas estavam organizadas para defender seus novos direitos e, portanto, as relações de força estavam a favor destas. Taticamente, por parte das comunidades, o jogo foi bem jogado, mas estrategicamente é provável que o esforço não tenha valido a pena, visto que, por ser estrangeiro, o fazendeiro em questão era, de certa maneira, pouco representativo do sistema de poder local, e a invasão de sua fazenda foi menos emblemática do que parecia inicialmente, pois não atingiu o sistema de dominação. Além disso, esta ação não obteve aprovação total entre os quilombolas.

Tudo isso para mostrar o quanto essas relações assimétricas entre fazendeiros e quilombolas muitas vezes têm gerado uma relação tensa, resultante da forma como os protagonistas conseguem assumir, através de acordos geralmente desvantajosos para as famílias quilombolas, as relações conflituosas que os permeiam. Atualmente, a partir da organização do movimento social quilombola, tais arranjos não tem sido sequer citados e os conflitos tendem a ser mais evidenciados.

\section{AS CARACTERÍSTICAS DO SISTEMA DE PODER LOCAL}

Em Salvaterra, esta semelhança de situações resultate da permanência do sistema de dominação herdado do período colonial também se evidencia, sobretudo nas relações diretas mantidas entre os membros das comunidades e o poder local. As entrevistas demonstraram como esse sistema de dominação contribuiu para criar um clima geral de medo, em razão da importância do controle exercido pelo prefeito nos peocedimentos eleitorais das populações, constrangendo cada uma das famílias e levando-as a se proteger contra os riscos de represália.

\subsection{O poder e a vida privada das populações}

Em entrevista concedida pelo prefeito atual, este descreveu minuciosamente a influência exercida pelo seu predecessor sobre os cidadãos, como se estivesse dentro da normalidade no contexto de Salvatera, em particular 
como conseguia obter uma adesão massiva dos habitantes de Salvaterra à Igreja Evangélica, que tem nesse personagem um de seus pilares. Esta "naturalização" do comportamento dos cidadãos em relação ao poder político permite pensar que essas formas de agir se justificam pela preocupação dos eleitores quanto ao cumprimento das promessas feitas pelo candidato à prefeitura - recompensas pelo voto - em honrar os compromissos assumidos pessoalmente junto a cada um de seus eleitores. E então, na medida em que o candidato assumia publicamente, durante a sua campanha, a vontade de apoiar a Igreja Evangélica, pelo lado dos eleitores, deixar a Igreja Católica ou outra religião aparecia como uma espécie de garantia suplementar, capaz de aumentar as chances de um cidadão assegurar o cumprimento das promessas feitas à título pessoal durante a campanha.

Esse comportamento dos eleitores não corresponde unicamente a um cálculo racional, algo oportuno. Em grande medida, ele é explicado pelo clima geral que envolve os compromissos do candidato. Baseados em promessas, esses compromissos são firmados sob o domínio do medo de represálias aos que não apoiarem o candidato eleito, conforme foi relatado por vários interlocutores. Essas represálias, das quais foi vítima a presidente de uma das comunidades, que narrou o caso da sua filha, que era contratada pelo serviço de limpeza e manutenção da prefeitura, mas não teve o seu contrato de trabalho renovado quando o prefeito soube que ela não havia votado nele. Embora o voto seja secreto, segundo ela, "todo mundo conhece todo mundo; é difícil de se esconder; se você vota é difícil de não se mostrar".

A importância do medo de represálias ou de que as promessas feitas pelo candidato durante a campanha não sejam cumpridas para explicar o comportamento dos cidadãos foi verificada na fala de grande parte das pessoas entrevistadas, o que demonstra o caráter permanente deste medo, instaurando um clima geral gerado não somente pelo temor de represálias por parte do político eleito, mas também pela suspeita de denúncias que possam ser feitas pelos vizinhos. Esse clima de temor e suspeição foi intensidicado, particularmente durante os dois mandatos do prefeito anterior. Segundo o relato de um ex-presidente da Câmara de Vereadores, para quem o sistema de poder local é totalmente corrompido e a justiça não tem capacidade de assumir suas responsabilidades, "é muito difícil para os cidadãos falarem dessa situação porque a corrupção é muito grande e as populações vivem desse poder". Neste contexto, o detentor desse poder é o prefeito em pessoa, aquele que "sai sempre ganhando, não importa o que aconteça, pois seus adversários se encontram totalmente desprovidos". De fato, foram impetradas pelo menos 40 ações na Justiça contra o chefe do governo anterior, durante os seus dois mandatos, mas até o presente momento em nada resultou. 


\subsection{Distribuição de contratos precários de trabalho como manifestação do sistema de poder}

O ambiente mantido sob um clima de medo, suspeição e necessidade de proteção, que obriga os adversários do poder a desenvolver estratégias individuais de defesa, vem testemunhando a perenização do sistema de dominação sobre o qual se apóia o poder local. Trata-se de sistema caracterizado por uma neutralização dos outros poderes governamentais - sobretudo o poder judiciário - e exercido notadamente através da chantagem permanente praticada pelo governante local sobre os cidadãos, graças a uma gestão hábil e perversa dos empregos públicos. Em tal contexto, a forma de gerir esses empregos torna-se a fonte principal de um poder discricionário, cuja autoridade se assenta na manutenção de um tipo de dominação ainda mais perverso, uma vez que havia neutralizado o judiciário, o poder que teria competência para impedir os abusos. O bom uso destea recursos por parte do governante local, consiste então em conservar muito discretamente um percentual importante dos postos de trabalho no serviço público ocupados por servidores contratados em regime temporário. A renovação anual desses contratos depende da vontade do governante e, sendo assim, o poder depende em grande parte da habilidade em manter os concidadãos sob pressão permanente, ameaçando de não efetuar a renovação dos seus contratos de trabalho, ano após ano.

O caráter eminentemente estratégico deste recurso é comprovado pela impossibilidade de obter a quantidade necessária de empregos mediante contrato temporário junto aos órgãos públicos, apesar das múltiplas tentativas feitas durante a pesquisa. O presidente da Câmara de Vereadores da administração anterior mencionou 1.800 empregos $^{8}$, o prefeito atual, que também não precisou os números, referiu, no entanto, que $90 \%$ dos postos de trabalho assalariados em Salvaterra eram da Prefeitura. O secretário de educação, contatado somente algumas semanas após a sua posse ${ }^{9}$, em março de 2013, mencionou 900 postos ocupados mediante contratação temporária apenas no setor educional - um setor encarregado do funcionamento de 57 escolas municipais, 14 destas situadas nas comunidades quilombolas. De todo modo, o cruzamento das informações obtidas por meio de várias fontes permite estimar em $90 \%$ o percentual de postos do serviço público no município de Salvaterra ocupados por pessoas contratadas temporariamente.

A precariedade desses empregos resulta dessa renovação de contrato negociada caso a caso, segundo afirmou o secretário de educação a respeito do

\footnotetext{
A título de esclarecimento, para um município de 20.000 habitantes, a disponibilidade de 1.800 vagas de trabalho no serviço público significa a possibilidade de oferecer, em média, um emprego para cada família.

9 A nova equipe de governo tomou posse em $1^{\circ}$ de janeiro de 2013.
} 
funcionamento dos contratos no setor da educação pública. Neste caso, a maior parte dos contratos haviam sido encerrados no final de 2012, e que em março de 2013 a Secretaria de Educação estava trabalhando em regime de urgência na renovação dos contratos necessários, sobretudo para manter o funcionamento das escolas. O cruzamento com outras fontes de informação permitiu verificar que esta situação não resultava da mudança da equipe de gestão municipal, visto que era renovada a cada ano nesse mesmo período. $O$ modo de gestão que deu origem a tal situação permite à Prefeitura economize um ou dois meses de despesas com salários a cada ano, uma vez que os contratos encerram no final do ano e o processo de renovação inicia após um ou dois meses do ano seguinte. Isso significa que há uma vacância dos postos de trabalho durante o período de férias escolares.

Compreende-se facilmente a relação de dependência gerada por um procedimento que afeta todas as famílias cujos rendimentos geralmente são baixos e provenientes das aposentadoriais dos avós, de bolsas dos programas governamentais (em particular a bolsa família) e, entre as mais favorecidas, do salário de um de seus membros.

\subsection{Um sistema de poder complexo}

O secretário de educação reconheceu que a resolução desse problema constituía um grande desafio para o prefeito atual, e que este gestor havia se comprometido em enfrentá-lo durante o seu mandato. No entanto, mesmo o prefeito tendo demonstrado total consciência ao ser consultado sobre o assunto durante a pesquisa, para ele não era evidente que a solução poderia ser a realização de concurso público, pois temia que o baixo nível de escolaridade dos potenciais candidatos locais levasse a uma ocupação dos postos por candidatos vindos de fora, e que estes não estariam necessariamente dispostos a investir no trabalho: "você vai abrir uma brecha; as pessoas de fora virão fazer o concurso, mas depois o que vai acontecer? Há um risco e é necessário avaliar a importância desse risco". O receio do prefeito tem fundamento na medida em que há efetivamente o risco de agravar a situação, pois sob o pretexto de manter um serviço público de qualidade, realizam-se concursos e as pessoas aprovadas não estão motivadas suficientemente para investir em uma mudança de domicílio, numa profissão como a de professor de nível fundamental e médio etc. Ao mesmo tempo, é possível constatar que este fato permite ao sistema político local conservar os principais atributos de seu poder. Dificilmente, nessas condições, seria possível superar tal dilema sem que ocorra um verdadeiro debate público sobre o desafio que representa uma reforma nesse sistema. Esta contradição 
demonstra a dificuldade de encontrar uma solução satisfatória para essa situação de dependência, mesmo havendo uma vontade política de mudança. Isso é uma prova da permanência de um sistema de dominação contra o qual é difícil lutar, cujos efeitos serão mantidos enquanto este poder não for questionado.

Esta situação explica, em parte, o dilema em que se encontra tanto o poder público quanto a população local; de um lado, o prefeito demonstra a vontade de mudança, porém, de difícil concretização; e, de outro, as comunidades quilombolas encontram dificuldades em transformar a capacidade de mobilização em defesa de novos direitos, em engajamento político. Neste contexto, por parte do prefeito o não reconhecimento de que as mudanças essencais para que seu município entre na modernidade dizem respeito tanto à ordem material (a construção de uma praça pública que seria emblemática para a cidade) quanto à ordem cognitiva (o que pensam as comunidades) e à ordem simbólica (o que este espaço representa para a população), interpela a ordem social local, estruturada sob a forma de um sistema de dominação que se mantém há décadas, sem compartilhamento dos serviços ou benefícios com essas populações. No entanto, o prefeito em questão é capaz de descrever a influência que exerce sobre os cidadãos, não somente pelo seu carisma pessoal, mas principalmente pela sua função e, portanto, do poder a ela associado. É dessa forma que ele justifica o movimento de adesão à Igreja Evangélica em decorrência da eleição do seu predecessor - movimento já referido anteriormente. Além disso, ele acredita que o seu vínculo com a Igreja Católica pode levar a uma influência semelhante, em outro sentido. Porém, essa constatação não leva o prefeito a explicar as razões desta influência, senão pelo fato de considerá-la consolidada.

Do lado das comunidades quilombolas, segundo a apreciação de uma das líderes do movimento pelos direitos socioterritoriais em Salvaterra, esta situação contribui para a que não haja, até hoje, "uma consciência do desafio político que é encontrar solução para os problemas". Esta falta de consciência política se manifesta especialmente na dificuldade de organizar uma frente comum dentro de uma maioria política. $\mathrm{Na}$ verdade, os quilombolas conhecem os seus direitos, porém eles têm inúmeras razões para não se envolver em denúncias públicas visando defender os direitos em questão, devido ao clima de tensão em cada uma das famílias quanto ao engajamento político, pela preocupação em não prejudicar o cumprimento das promessas feitas pelos candidatos durante as campanhas eleitorais. Eis a razão pela qual eles têm escolhido privilegiar estratégias individuais em termos políticos, pois estão convencidos de que "as pessoas que se engajam contra o sistema político correm o risco de ficar de fora do sistema" (Entrevista com a líder política). 
Tal dificuldade tem origem, em parte, no dispositivo legal proposto pela Constituição para tratar da situação dos quilombolas. Trata-se de um quadro diferente das Reservas Extrativistas, que visa melhorar a situação das populações tradicionais, estimulando-as a se organizar e a se mobilizar coletivamente para satisfazer as exigências do desenvolvimento sustentável em seus territórios, garantindo-lhes um espaço deliberativo e apoios importantes em termos de assessoria técnica e de ferramentas diversas. No caso dos quilombolas, esse dispositivo lecal não prevê o reconhecimento dos direitos das comunidades no sentido de garantir-lhes novos suportes e ferramentas específicas para orientar a sua produção e atuação social, em especial, não lhes garante uma instância deliberativa que possa legitimar a sua participação enquanto ator político para apreender, com o poder local, as consequências desse reconhecimento. $\mathrm{O}$ incentivo proposto pela Constituição de 1988 às comunidades quilombolas para defender seus novos direitos consiste em satisfazer as exigências constitucionais autodefinindo-se como quilombolas e organizando-se em associações para assim tratar diretamente com os agentes do governo federal. Porém, enquanto cidadãos, os membros dessas comunidades, de algum modo, tem sua liberdade de ação muito limitada em relação a um governo local marcado pela permanência de um sistema de dominação que impõe suas próprias regras. Neste sentido, é adequado apresentar, na sequência, a experiência das Resex.

\section{DENÚNCIA DO AVIAMENTO: CONTRIBUIÇÃO DAS RESEX À TRANSFORMAÇÃO DO PODER LOCAL}

O exemplo das Resex confirma a importância atribuída à permanência do sistema de dominação herdado do período colonial, à influência por ele exercida no sistema de poder local e à dificuldade em produzir mudanças sustentáveis nos territórios quanto ao exercício do poder local, se tais mudanças não põem em questão esse próprio sistema de dominação.

Segundo Teisserenc (2010), a Resex foi apresentada como um instrumento de política pública - no caso, a política ambiental brasileira -, sublinhandose a originalidade deste instrumento, visto que foi elaborado e experimentado pelos movimentos sociais e não, como é habitual, pelos experts da administração público-administrativa, além do mais, a sua adoção pelo governo brasileiro, após a retomada da democracia, fez-se acompanhar de inúmeras medidas iniciadas, em parte, pelos próprios movimentos sociais, cujas aplicações contribuíram para colocar em xeque o sistema de dominação hegemônico. Antes de demonstrar como a sua aplicação possibilitou criar condições favoráveis para o questionamento 
desse sistema de dominação e para o surgimento de novas práticas políticas em nível local, convém lembrar algumas dessas medidas.

No início deste artigo, ao descrever o aviamento como um sistema de dominação remanescente do ciclo da borracha, mostrou-se como o seringueiro, conhecedor de um território no qual exercia suas atividades de coleta, tornouse, ao mesmo tempo, tributário de uma relação de poder de natureza clientelista em relação a um patrão, o seringalista, e que isso caracterizou fortemente a sua identidade. A imposição desta identidade e a sua permanência para além do ciclo da borracha explicam porque o movimento social no qual se apoiou Chico Mendes e seus companheiros de luta em 1975, em Brasiléia, no estado do Acre, Noroeste do Brasil, sob a ditadura militar, organizou-se com base em uma pauta de reivindicações por garantias de condições adequadas de vida e trabalho na floresta para os seringueiros, explorando os seus recursos enquanto trabalhadores independentes e, desse modo, não subordinados aos patrões. Isso exigiu o reconhecimento de um estatuto de trabalhador independente, e o usufruto de um território no qual pudesse exercer suas capacidades em termos de valorização e gestão da biodiversidade - assim chamada pelos ambientalistas aliados do movimento dos seringueiros. Para este reconhecimento, a criação do Sindicato dos Trabalhadores Rurais (STR) contribuiu significativamente para manter uma estrutrua permanente de articulação e de suporte às reivindicações dos seringueiros.

Em um contexto de retomada da democracia no Brasil, enquanto se ampliava a exploração predatória dos recursos naturais na Amazônia, cujo efeito mais visível era o desflorestamento, surgiu a ideia de criar Unidades de Conservação (UC), segundo a qual o modelo da Reserva Indígena, que dava resultados satisfatórios em termos de proteção dos direitos indígenas e conservação dos recursos naturais, poderia ser utilizado como referência de um projeto de desenvolvimento sintonizado com a proteção ambiental. Rapidamente esta ideia ganha adesão, aproveitando, sobretudo, a grande mobilização camponesa que acompanhou o processo de redemocratização do país. Esta mobilização foi o marco histórico que deu origem ao Conselho Nacional dos Seringueiros (CNS) e ao Instituto de Estudos Amazônicos (IEA) durante a realização do primeiro Encontro Nacional dos Seringueiros, em 1985.

Nessa conjuntura muito particular foi consolidade o projeto da Reserva Extrativista destinada a proteger os trabalhadores rurais e suas famílias, identificados também pela Constituição de 1988 como populações tradicionais, aquelas que viviem da exploração dos recursos naturais de seus territórios. Como resultado da mobilização dos camponeses e da aliança desse movimento com 
outros segmentos de populações tradicionais, com o objetivo de garantir a esse coletivo a permanência na floresta, graças à implantação de uma reforma agrária que respeitasse o seu modo de vida tradicional ${ }^{10}$, a Reserva Extrativista ganha corpo. Mas é também graças à modernização de seus métodos de trabalho, com o apoio de serviços competentes ${ }^{11}$, que a solução proposta pelos e para os seringueiros afirma a sua legitimidade e se impõe como resultado de sua mobilização.

O assassinato de Chico Mendes, em dezembro de 1988, e o impacto internacional desse evento forçou o governo a tomar medidas no âmbito da estrutura de gestão da política ambiental e, nesse contexto, um ano depois foi criado o Instituto Brasileiro do Ambiente e dos Recursos Naturais Renováveis (Ibama), passando a compor, juntamente com o Sistema Nacional de Meio Ambiente (Sisnama), o Conselho Nacional do Meio Ambiente (Conama) e o Ministério do Meio Ambiente, criado no início dos anos de 1980, o conjunto institucional do governo brasileiro voltado para o Meio Ambiente. E será este conjunto - e não outro - que acolherá o projeto de Reserva Extrativista.

Pouco mais de três anos após o assassinato de Chico Mendes, em fevereiro de 1992, para viabilizar a implementação das Reservas Extrativistas, no Ibama foi criado o Centro Nacional de Desenvolvimento Sustentado das Populações Tradicionais (CNPT), uma uma estrutura para promover o diálogo e a cooperação entre as populações tradicionais e o poder público. Para o Estado, o CNPT equivalia ao que o CNS representava para a sociedade civil.

Nesse cenário, o princípio constitucional ambiental propiciou debates que permitiram ao movimento social composto pelos camponeses livres (CNS) e a um grupo de pesquisadores retomarem a experiência implantata por Chico Mendes no Acre, condiderada inovadora tando do ponto de vista ambiental quanto em termos de organização social e de um modo de ocupação do espaço amazônico que colocava em xeque a propriedade da terra e as relações do homem com a natureza, assim como o sistema de dominação política que prevalecia ali até então.

Os reflexos desses debates são, em parte, bem conhecidos: em termos de ocupação da terra, o projeto de Reserva Extrativista preconiza que a terra é de propriedade do Estado brasileiro, que a concede para o usufruto de uma

10 Ver Capobianco (2001), em especial o capítulo "Formas de acesso à terra e a preservação da floresta amazônica: uma análise jurídica da regularização fundiária das terras dos quilombolas e seringueiros" (BENATTI, 2001, p. 292-298).

11 Foi realizado em Curitiba, em setembro de 1988, o seminário Planejamento e Gestão do Processo de Criação das Reservas Extrativistas na Amazônia, reunindo instituições universitárias, associações indígenas e o CNS. Um dos resultados deste seminário foi a elaboração de uma declaração atribuindo grande importância ao lugar da sociedade civil nos projetos de valorização da Amazônia. 
comunidade $^{12}$. Nesta concepção, é reconhecido o direito das populações tradicionais de explorar a biodiversidade de um território de forma sustentável, por meio do extrativismo, a partir de um modelo de gestão compartilhada por essas populações, com o aval das autoridades públicas federais. No que concerne à relação do homem com a natureza, o extrativismo é definido como uma atividade econômica viável, em um sistema econômico e social em que a floresta não é mais considerada como uma plataforma de recursos a ser explorada pelo capital, mas uma fornecedora de bens e de serviços. Como resultado disso, para que as populações ontenham o reconhecimento jurídico do direito à terra e das restrições de uso, os princípios ambientais precisam ser respeitados. Portanto, tal reconhecimento põe em xeque um contrato implícito entre as populações contempladas e o poder público que as apoiam com os meios técnicos, recursos financeiros e ferramentas de assessoria à gestão do território da Reserva - dentre estas, os diagnósticos e os planos de uso e de gestão. É preciso lembrar que o uso dessas ferramentas e a gestão desses meios são de competência de um conselho deliberativo, uma instância com atribuição técnica e política que reúne, de modo paritário e dentro de uma lógica participativa, representantes de comunidades usuárias da Resex e seus principais parceiros.

Concebido desta maneira, o projeto de Reserva Extrativista contribui para a criação de um retorno de percepção, na medida em que a sua implementação é acompanhada de uma requalificação das populações tradicionais e do reconhecimento de seu território. Este último se apresenta como um espaço reivindicado pelas comunidades que ali vivem e que oferece um quadro no qual podem se desenvolver, segundo Deborah de Magalhães Lima, "experiências muito inovadoras que permitem pensar novos modelos para uma sociedade futura e a emergência de uma racionalidade ambiental que interroga a racionalidade capitalista" (MAGALHÃES LIMA, 2002, p. 17).

Mesmo que de todos os pontos desta interpretação não se compartilhe algo muito téorico e idealista dos desafios enfrentados pela criação das $\operatorname{Resex}^{13}$, a ideia de que a Reserva oferece um estatuto às populações tradicionais e lhes reconhece o direito de uso de um território no qual elas desenvolvam não somente um modo de produção original capaz de satisfazer as exigências ambientais, assim como uma forma de ocupação capaz de responder às suas próprias expectativas, e

12 Criadas por decreto presidencial, as Reservas Extrativistas são definidas como espaços territoriais pertencentes à União, destinadas à utilização sustentável e à conservação dos recursos naturais renováveis pela população que trabalha tradicionalmente com os produtos da floresta. Elas são objeto de uma concessão de direito de uso à população extrativista, de acordo com um plano de utilização aprovado pelo Ibama.

13 Para a autora, o desafio da criação da Resex está na emergência de uma "democracia ambiental" capaz de se impor no nível territorial enquanto modelo de democracia local. 
que, de certo modo, cria condições favoráveis ao questionamento das relações de dependência resultantes do sistema tradicional, em prol das relações contratuais entre as comunidades e os representantes do poder federal, e também entre essas mesmas comunidades e o poder local.

Nas pesquisas conduzidas em três Resex na Amazônia nos últimos anos, foi confirmada a nossa interpretação. Os resultados mostraram como a criação dessas áreas protegidas promoveu transformações na situação econômica e social das populações tradicionais organizadas em comunidades (TEISSERENC, 2014), mas igualmente trouxe mudanças na postura política dessas populações, interpelando assim o sistema de poder local. As Resex em questão são: Mãe Grande de Curuçá e São João da Ponta, situadas, respectivamente, nos municípios de Curuçá e de São João da Ponta, no nordeste do Pará; e Verde para Sempren situada no município de Porto de Moz, no oeste do estado. Curuçá e São João da Ponta são reservas marinhas, ambas criadas em 2002; e a Verde para Sempre é uma reserva de terra firme, criada em 2004.

Nos três municípios abragidos pela criação dessas respectivas Resex foi constatado, às vésperas das eleições de 2008, que havia divisões territoriais, ficando, de um lado, o movimento social e o Conselho Deliberativo da Resex e, de outro, o sistema de poder local e suas instituições - Prefeitura e Câmara de Vereadores. Durante o mandato precedente não houve nesses territórios nenhuma iniciativa comum empreendida pelas instituições públicas. O poder local contentava-se em assegurar um trabalho administrativo no âmbito do município, segundo a sua própria lógica - a da representação - desenvolvendo práticas clientelistas e utilizando, a propósito, as instituições e os recursos públicos, sem levar em conta a existência de uma nova entidade representativa no âmbito local, após a criação da Resex - o Conselho Deliberativo - cujo funcionamento tira proveito dos recursos e da legitimidade conferida pelo poder central. Os dois organismos institucionais, a Prefeitura e a Câmara de Vereadores de um lado, e o Conselho Deliberativo de outro, conseguiram coexistir, mas sem encontrar meios para qualquer colaboração. A presença de ambas as instâncias em um mesmo território teve como principal consequência dar maior visibilidade a um conflito latente vivenciado no município ao longo do tempo, uma tensão social que resulta e é mantida pelo sistema de dominação desde o período colonial.

Nos três municípios, as eleições de 2008 constituíram um divisor de águas de suas histórias políticas, em razão das mudanças de alianças entre os atores locais, o que permitiu ao movimento social tornar-se agente do poder local. Entre os três municípios, o de situação mais estável é São João da Ponta, criado em 1995, ao se emancipar do município de São Caetano de Odivelas. Em São João da 
Ponta, a maioria dos eleitores é usuária da Reserva, e isso contribuiu para que o presidente da associação dos usuários se tornasse prefeito nas eleições de $2008^{14}$. Nos outros dois casos, a nova equipe foi constituída a partir de um jogo de alianças entre um representante de uma das famílias tradicionalmente detentoras do poder local e uma parte do movimento social ${ }^{15}$. Esse acordo eleitoral teria se baseado no compartilhamento de responsabilidades entre o prefeito e o viceprefeito, além da repartição dos cargos das secretarias entre os aliados.

De fato, o balanço provisório possível da situação de cada um dos municípios mostra que, à exceção de São João da Ponta, onde o prefeito atual conta com o apoio da maioria da população, na medida em que $60 \%$ do eleitorado faz parte da Resex, e onde a gestão local vem testemunhando sua fidelidade às orientações e valores desse instrumento. Nos outros dois municípios, o compromisso que deu origem à aliança sobre a qual se constituiu o novo poder local mostrou-se frágil ${ }^{16}$; uma fragilidade que tanto em Curuçá, como em Porto de Moz, o que foi confirmado nas eleições de 2012, pela não recondução das duas equipes ao poder.

Longe de descartar a nossa hipótese, esta não recondução pode ser interpretada como o sinal do funcionamento mais democrático das instituições

14 O primeiro prefeito de São João da Ponta governou o município por dois mandatos consecutivos - de 1997 a 2000, e de 2001 a 2008. Em 2008, o presidente da associação de usuários da Resex é foi eleito prefeito, e atualmente encontra-se no último ano de seu segundo mandato.

15 Em Porto de Moz, o prefeito eleito é sempre o representante de uma das famílias detentoras do poder local desde a criação do município, no final do século XIX (MOREIRA, 2007), que conseguiu fazer uma aliança com líderes do movimento social para ganhar as eleições, contra o representante de outra família tradicional. Em Curuçá, o prefeito é o herdeiro de uma família importante da região, industrial dinâmico e ambicioso, preocupado em promover uma gestão local moderna, que fez aliança com um técnico da Emater, que era militante formado nas pastorais da Igreja católica, com participação ativa na criação da Resex. Considerado como um dos representantes do movimento social e da ala progressista da Igreja Católica, cujo papel foi decisivo nesse processo, este técnico aceitou a proposta de aliança atendendo às expectativas do movimento.

16 Em Porto de Moz, esta fragilidade manifestou-se em importantes fraturas no âmbito do movimento social, no qual muitos membros não aceitaram alianças consideradas ideologicamente incompatíveis. Em Curuçá, ela se manifestou por dissenções entre o prefeito e o vice-prefeito, a tal ponto que este último se viu obrigado a deixar o seu local de trabalho na prefeitura e instalar o seu gabinete na própria residência. Esta fragilidade se manifestou igualmente pelo fato de que durante os dois primeiros anos do mandato o prefeito jamais teria se preocupado ou se ocupado da Reserva, delegando ao seu vice a total responsabilidade pelos assuntos da Resex. Esta situação perdurou até o fim do terceiro ano de mandado, quando o prefeito passou a se preocupar com a reeleição, para evitar uma ruptura de aliança e o risco de uma possível candidatura do seu vice, demonstrou o interesse pela gestão da Reserva, participando regularmente das reuniões do Conselho. A esse concurso de circunstâncias acrescentou-se a possibilidade iminente da realização do projeto de um grande porto marítimo na área da Reserva, capaz, segundo os especialistas, de provovar uma catástrofe ecológica no conjunto de ecossistema regional de manguezal. Trata-se de um projeto ao qual o prefeito posiciosava-se contra a sua implantação, por isso, mais próximo dos objetivos do movimento social. 
locais. Durante os quatro anos de governo local com um novo sistema de poder, assistiram-se a uma renovação importante das práticas democráticas, graças a um investimento significativo de uma parte dos parceiros locais no Conselho Deliberativo. Foi assim que, a exemplo do seu colega de São João da Ponta, o prefeito de Curuçá decidiu que ele próprio seria o representante da prefeitura neste espaço, e não o secretário do meio ambiente, como é habitual. Essa decisão foi tomada para que o prefeito participasse diretamente das deliberações. Incontestavelmente, esta forma de atuação reforçou a legitimidade do Conselho e, mais ainda, do trabalho que realiza com o aval da entidade. Este trabalho configura-se como o resultado de uma experiência baseada nas práticas participativas iniciadas no âmbito da Reserva, e que acabou por interferir no sistema de poder local.

Segundo as considerações de Teisserenc (2014) sobre a experiência do Conselho Deliberativo de Curuçá, este espaço se impôs como uma arena de debates públicos, que concerne ao conjunto das populações e ao conjunto do território, mesmo quando as pessoas ignoram o que seja uma Reserva e seus interesses, como observado por Aloma de Vasconcelos (2010). Os debates que ocorrem no Conselho são oportunidades de fortalecer as experiências democráticas que abrangem todos os segmentos do território e levam em conta os interesses das comunidades representadas, tanto que os membros do Conselho tendem a se impor como "novos atores políticos" capazes de negociar compromissos.

A busca de tais compromissos deixa entender que o Conselho se apresenta como o lugar onde tournou-se possível apreender os conflitos que marcaram a história de cada um desses municípios desde sua criação e que o funcionamento desse espaço oportuniza a busca de conciliação, a superação de antagonismos, em nome de um bem comum ambiental e social no âmbito da Reserva (VASCONCELOS, 2010, p. 211).

\section{CONSIDERAÇÕES FINAIS}

Observar a experiência das Reservas Extrativistas leva à compreensão das formas como o sistema de dominação tradicional permanece atuando até hoje. Ao buscar demonstrar as condições para o êxito desse instrumento de política pública, a sua capacidade de influenciar na organização do poder local emerge como um aspecto relevante. Ao colocar em xeque o sistema de dominação que prevalece até os dias atuais, a implementação da Reserva Extrativista favorece as mudanças na organização do poder local. 
Voltando agora à situação das comunidades quilombolas de Salvaterra que sofrem as influências desse poder local, e até hoje não conseguiram modificar a sua natureza, elas se inscrevem, à sua maneira, em uma trajetória similar a das populações tradicionais das Reservas Extrativistas, demonstrando capacidade de mobilização coletiva em defesa de seus direitos.

Entretanto, esta capacidade de mobilização limita-se à defesa de seus direitos, sem que isso represente uma "tentativa de autonomia institucionalizada". Por exemplo, o tratamento dado a uma quilombola pelo prefeito anterior sem ter procado uma reação coletiva de sua comunidade e do movimento quilombola testemunha a dificuldade de enfrentar e superar a situação de dominação. No caso, tratava-sese de uma mulher, membro de uma das comunidades, que lutava pelo reconhecimento do caráter sagrado da natureza como elemento justificador da reivindicação do direito à terra. A mulher em questão perdeu o apoio de sua comunidade a partir do momento em que o prefeito, percebendo os riscos de tal engajamento, empregou todos os estratagemas à sua disposição para pressionar a comunidade - em particular o seu vínculo com a Igreja Evangélica. A eficácia da intervenção foi uma prova significativa do poder e da influência exercida pelo prefeito, sem que fosse necessária uma atuação mais efetiva do governo municipal nem dos serviços públicos em prol das comunidades. As ações foram praticamente inexistentes, pois a política de desenvolvimento do território e de gestão de pessoal do município conduzidas por ele jamais favoreceram as comunidades quilombolas e seus membros. Logicamente, tais práticas discricionárias encorajaram uma mobilização política das comunidades na campanha para as eleições municipais de 2012, com o objetivo de pressionar o poder local e de se constituir em força política. Mas tal conquista não se consolidou, testemunhando assim que, diferente do demonstrado nas experiências das Resex, a mobilização das comunidades quilombolas pela defesa de seus direitos não conseguiu se transformar em uma mobilização política, visto que o aparato jurídico instituído pela Constituição de 1988 para resolver esta situação problemática não cria as condições necessárias para recolocar em xeque o sistema de dominação que as oprime, da mesma forma que afeta a maioria da população local ${ }^{17}$, enquanto o poder local exerce uma grande influência na situação dessas comunidades. Nesse contexto, o engajamento político dos membros das comunidades tem origem em um trabalho clássico de politização dos indivíduos e dos grupos sociais, com base na sua condição e em função da sua capacidade de organização coletiva. A análise desse tipo de engajamento justifica a elaboração de outros artigos, dando continuidade à reflexão desenvolvida neste trabalho.

17 Em um próximo artigo será tratado o engajamento político das comunidades quilombolas de Salvaterra. 


\section{REFERÊNCIAS}

ADORNO, T. et al. La personalidad autoritaria (Prefacio, Introdución y Conclusiones). Empiria - Revista de Metodología de Ciencias Sociales, n. 12, p.155-200, jul.-dic. 2006.

AUBERTIN, C. Les Réserves extractivistes: un nouveau modèle pour l'Amazonie? In: ALBALADEJO, Christophe; TULET, Jean-Christian (Dir.). Fronts pionniers de l'Amazonie brésilienne. Paris: l'Harmattan, 1996. p. 102-115.

BENATTI, J. H. Formas de acesso à terra e a preservação da floresta amazônica: uma análise jurídica da regularização fundiária das terras dos quilombolas e seringueiros. In: CAPOBIANCO, J. P. (Org.). Biodiversidade na Amazônia brasileira: avaliação e ações prioritárias para a conservação, uso sustentável e repartição de benefícios São Paulo: Estação Liberdade, Instituto Socioambiental, 2001. p. 292-298.

BOURDIEU, P. Questions de Sociologie. Paris: Minuit, 1984.

BROGGIO, C.; DROULERS, M. Démocratisation et territoire au Brésil. Revue Geocarrefour, v. 81, n. 3, p. 223-233, 2006.

CAPOBIANCO, J. P. (Org.). Biodiversidade na Amazônia Brasileira. São Paulo: Estação Liberdade; Instituto Socioambiental, 2001. 544p

CROZIER, M. Le phénomène bureaucratique. Paris: Ed. du Seuil, 1964.

FAURE, A. La question territoriale. Pouvoirs locaux, action publique et politique. [s.l.]: HDR, IEP de Grenoble, 2002.

GOMES, F. dos S. A hidra e os pântanos. Mocambos, quilombos e comunidades de fugitivos no Brasil (Séculos XVII-XIX). São Paulo: Ed. Unesp; Polis, 2005.

GREMION, P. Le pouvoir périphérique. Bureaucrates et notables dans le système politique français. Paris: Seuil, 1976.

LEFF, E. Racionalidade Ambiental - a reapropriação social da natureza. Rio de Janeiro: Civilização Brasileira, 2006.

MABILEAU, A. Le système local en France. Paris: Editions Montchrestien, 1995.

MAGALHÃES LIMA, D. de. Éthique et politique environnementale en Amazonie contemporaine. Lusotopie, v. 1, p. 13-23, 2002. 
MOREIRA, E. S. S. (2007), Movimento social Amazônico em defesa de Territórios e de modos de vida rurais: estudo socilógico no Baixo Xingu. Tese de doutorado. Programa de Pos Graduação em Ciências Sociais, Universidade Federal do Pará, co-tutela com Universidade Paris 13. Sob a direção de Jean HÉBETTE et de Pierre TEISSERENC 290 p

O'DWYER, E. C. Remanescentes de quilombolas na fronteira amazônica: a etnicidade como instrumento da luta pela terra. Boletim Rede Amazônia, ano 1, n.1, p. 77-88, 2002.

QUEIROZ, M. I. P. Mandonismo local na vida política brasileira e outros ensaios. São Paulo: Alfa-Ômega, 1976.

SANTILLI, J. Socioambientalismo e novos direitos - proteção jurídica à diversidade biológica e cultural. São Paulo: Peirópolis, 2005.

TEISSERENC, P. Reconhecimento de saberes locais em contexto de ambientalização. Belém, UFPA/NAEA, Novos Cadernos NAEA, v. 13. n. 2, jan-jun, 2010, p. 5-25.

TEISSERENC, P. A governança territorial em Reservas Extrativistas. Revista Pós-Ciências Sociais, v. 11, n. 22, p. 19-41, jul.-dez. 2014.

TEISSERENC, P. Les Resex, un instrument au service des politiques de développement durable en Amazonie brésilienn. Revista Pós-Ciências Sociais, v. 6 , n. 12, p. 41-68, 2010.

VASCONCELOS, A. T. Gestão pública e participação: uma análise do Conselho Delibertivo da Reserva Extrativista Mãe Grande de Curuçá. 2010. 176f. Dissertaçao (Mestrado) - Núcleo de Meio Ambiente, Universidade Federal do Pará, Belém, 2010. 